\title{
Evaluation of a Web Course on the Basics of Gynecological Laparoscopy in Resident Training
}

\section{Jokinen, Ewa}

2017

Jokinen , E , Mikkola , T S \& Harkki , P 2017 , ' Evaluation of a Web Course on the Basics of Gynecological Laparoscopy in Resident Training ' , Journal of Surgical Education , vol. 74 , no. 4 , pp. 717-723 . https://doi.org/10.1016/j.jsurg.2016.12.007

http://hdl.handle.net/10138/297838

https://doi.org/10.1016/j.jsurg.2016.12.007

publishedVersion

Downloaded from Helda, University of Helsinki institutional repository.

This is an electronic reprint of the original article.

This reprint may differ from the original in pagination and typographic detail.

Please cite the original version. 


\title{
Evaluation of a Web Course on the Basics of Gynecological Laparoscopy in Resident Training
}

\author{
Ewa Jokinen, $M D,{ }^{*}$ Tomi S. Mikkola, MD, PhD, ${ }^{\dagger}$ and Päivi Härkki, MD, $P h D^{\dagger}$ \\ *Obstetrics and Gynecology, Hyvinkää Hospital, University of Helsinki, Hyvinkää, Finland; and ${ }^{\dagger}$ Obstetrics \\ and Gynecology, Helsinki University Hospital, Helsinki, Finland
}

OBJECTIVES: Reduction in the number of gynecological operations has made resident training more difficult in gynecological surgery. We used electronic educational material to supplement traditional apprentice model in resident surgical education. Our aim was to evaluate effectiveness of a web-based course in knowledge gaining among residents with various levels of clinical experience.

DESIGN: In prospective interventional study, the level of knowledge was assessed before and after taking the course.

SETTING: All Finnish residents in obstetrics and gynecology were invited to participate.

PARTICIPANTS: Fifty-eight voluntary residents from all 5 University districts were allocated in 3 groups according to the experience.

RESULTS: Fifty-eight residents replied to the precourse questionnaire, and $33(57 \%)$ of them filled in the postcourse questionnaire. Significant knowledge gain was detected in each experience group. In the less experienced group, the mean score (max: 110) increased from 81.9 to $89.3(\mathrm{p}=0.009)$, in the middle group from 90.4 to 97.9 $(\mathrm{p}=0.003)$, and in the most experienced group from 94.8 to $100.0(\mathrm{p}=0.017)$. The participants rated the usefulness of the course as 4.8 in the Likert scale 1 to 5 , and all intended to return to the course.

CONCLUSIONS: We found a significant increase in scores in every level of clinical experience. Thus, the course could be used as an educational tool. ( $\mathrm{J}$ Surg Ed 74:717-723. () 2017 Association of Program Directors in Surgery. Published by Elsevier Inc. All rights reserved.)

KEY WORDS: surgical education, resident education, e-learning, theoretical knowledge, laparoscopy

Correspondence: Inquiries to Ewa Jokinen, MD, Obstetrics and Gynecology, Hyvinkää Hospital, University of Helsinki, Sairaalankatu 1, 05850 Hyvinkää, Finland; fax: +(358)19-4587-2358; e-mail: ewa.jokinen@hus.fi
COMPETENCIES: Patient Care, Medical Knowledge, Practice-Based Learning and Improvement

\section{INTRODUCTION}

Gynecological surgery has changed during recent decades as laparoscopy became more popular. In addition, educational reforms and restrictions on working hours have caused a significant reduction in surgical hands-on training exposure, ${ }^{1}$ and at the same time, the increased use of endoscopic surgery has made training even more challenging and timedemanding. The surgical caseload, especially the proportion of benign surgery in Finland (statistics of the National Institute for Health and Welfare in Finland), has also decreased. Thus, relying only on operating room experience is insufficient to fulfil current demands for surgical education and training.

The residents should have basic surgical knowledge and skills before entering the operating room to benefit most from the actual operations. This would also allow the residents to focus on the precise case, on nontechnical skills, and on teamwork. Psychomotor skills are best learned with simulators, and various methods have been implemented for training technical skills. ${ }^{2-4}$ Theoretical knowledge has traditionally been gained from books, lectures, and courses, alongside clinical work. ${ }^{5}$ These sources are currently being partially replaced by information technology; the new generation is more technology-oriented ${ }^{6}$ and more motivated to seek information from electronic media.

Electronic learning (e-learning) offers new possibilities for surgical education with modern methods such as blended learning, spaced education, and flipped classrooms. E-learning has many advantages compared to traditional sources. The former allows for versatile use of pictures, videos, animations, and texts. Web courses are easy to access and update, allowing personalized learning. ${ }^{8}$ Moreover, the course material is standardized, and an instructor's attendance is not required. ${ }^{, 10}$ Disadvantages include high initial cost, need for programming 
expertise, and the requirement of a high-speed Internet connection for the users. ${ }^{8}$

Many published endoscopic curricula have their own cognitive portions. Fundamentals of laparoscopic surgery in the United States is designed widely for residents in general surgery, urology, and gynecology, 2,11 and in Europe the European certification program of the European Academy of Gynecological Surgery for gynecologists. ${ }^{3}$ As individual countries may have specific national customs in practicing medicine, it is important to have a national cognitive course. Thus, with our web-based course with online testing, covering all basic areas of laparoscopic surgery, our aim was to evaluate its effectiveness for residents at various levels of clinical experience.

\section{MATERIALS AND METHODS}

The web-based, "Basics in Gynecological Laparoscopy," was developed in collaboration with the Finnish Medical Society Duodecim and the Finnish Society of Gynecological Surgery. Duodecim produces clinical guidelines, as well as webbased courses, and it also evaluates continuous medical education and supports research. Development of our webbased course started in May 2010, and the course was available on the Internet ${ }^{12}$ by February 2012. In addition to the Duodecim coordinator, our project group was composed of 7 experts in gynecological surgery. The composition of the course included both basics in gynecological laparoscopy and advanced information for specialists. The contents of the course are divided into the following 6 parts: pelvic anatomy, instrumentation, operative phases, gynecological operations, complications, and training possibilities (Table 1). The course contains abundant photos and videos in addition to written explanations. After completion of the course, there is a web-based test.

At the time the course was published, an effectiveness study was carried out: the level of knowledge was assessed before and after taking the web course. An invitation to participate was sent via e-mail in autumn 2011 to all obstetrics and gynecology $(\mathrm{OB} / \mathrm{GYN})$ residents under the Finnish Society of Obstetrics and Gynecology. The resultant list comprised 154 persons, but because in Finland the registration for specialist training is unregulated, the correct number of $\mathrm{OB} / \mathrm{GYN}$ residents at a given time was not known.

Two questionnaires were made to cover the most important areas of the topic with 29 mainly multiplechoice questions (Appendices 1 and 2). Each area was graded from 0 to 6 , and the total score was 110 . Questions were chosen among test questions in the main web course. The first questionnaire was sent in December 2011 to voluntary participants with 2 reminders. In the e-mail there was a link to the Internet-based query, which was to be filled in as a one-time examination. The participants received another information letter at the beginning of 2012 and were instructed to complete the course after its release in February 2012. The second questionnaire as a link with one-time examination was sent in May 2012 to those who filled in the first questionnaire, again with 2 reminders. The entire study was web-based and anonymous.

In the first questionnaire, the participants were asked about demographics (sex, age, medical faculty, working history, number of laparoscopic surgeries done, and use of specific surgical simulators). In the second questionnaire, we asked if they had worked in a surgical unit during the study (due to specialization) and for how long, how they graded the course (usefulness of the course on the Likert scale 1-5), and whether they intended to repeat the course.

Equivalent difficulty of the 2 questionnaires was demonstrated by a crossover design with statistical tests: prior to the course, half of the participants received questionnaire A while the others received questionnaire $\mathrm{B}$ in random order. After the course, each participant received the other questionnaire than the one in the beginning. At the pretest situation, groups $\mathrm{A}$ and $\mathrm{B}$ were equal in training time in OB/GYN ( $\mathrm{p}=0.297)$, in experience in operations done $(\mathrm{p}=0.964)$, and in questionnaire scores $(\mathrm{p}=0.122)$. The scores in the questionnaires correlated strongly to training time in OB/GYN $(r=0.668, \mathrm{p}<0.001)$ and in surgical experience $(r=0.557, \mathrm{p}<0.001)$. The construct validity was also demonstrated in the Kruskal-Wallis test, which revealed statistical significance in scores across experience in time in OB/GYN $(\mathrm{p}<0.001)$ and in surgical experience $(\mathrm{p}$ $<0.001)$.

To evaluate the interest in our web-based course more widely, number of downloads of different web course pages were obtained from Duodecim concerning the first 3-year period after the publication of the course. The number of downloads was available only if the page was among the 500 most downloaded pages of their 61 web courses.

\section{Ethics Approval}

The study plan was approved by the Helsinki University Hospital Ethics Committee (Dnro 390/13/03/03/2012).

\section{Statistical Analysis}

For the statistical analysis, the participants were allocated into 3 groups according to clinical experience, determined as training time in $\mathrm{OB} / \mathrm{GYN}(<18 \mathrm{mo}, 18-36 \mathrm{mo}$, or $>36 \mathrm{mo}$ ).

Statistical analysis was done with SPSS 21.0 statistical software (Chicago, IL). To investigate the equality of questionnaires A and B, we used the Independent-samples $t$-test for parametric continuous variables and the chi-square test for independence for nonparametric categorical variables. In the construct validity study for questionnaires, we used the Pearson Correlation test for parametric and the 
TABLE 1. The contents of the web-course 'Basics in Gynecological Laparoscopy'.

1. Pelvic anatomy

a. Normal anatomy

b. Pathological anatomy

2. Instrumentation

b. Laparoscopic unit

c. Additional instrumentation

d. Special instrumentation

e. Energy sources

3. Operative phases

a. Patient positioning, ergonomy

b. Entry

c. How to use optics

d. Abdominal check up

e. Operational plan

f. Operational techniques

4. Gynecological operations

5. Complications

6. Training possibilities

7. Test a. Tubal

b. Ovarian

c. Uterine

d. Endometriosis

e. Adhesiones

f. Laparocopic prolaps surgery

a. Entry

b. Vessels

c. Bladder and ureter

d. Bowel

a. Box simulator

b. Virtual simulator

c. Animal models
Pelvic organs

Vessels and ureters

Abdominal cavity

Tubal pathology

Ovarian pathology

Uterine pathology

Endometriosis

Veress needle

Trocars

Forceps and scissors

Uterine manipulators

Suction and irrigation

Insufflator

Light source

Light cable

Camera

Optics (laparoscopes)

Monitors

Documentation systems

Specimen retrieval bag

Endo loop ligature

Fascial closure instrument

Morcellator

Needle holders and knot tier Staplers

Ureteral imaging systems

Pelvic floor meshes

Tacks

Vessels clips

Hemostatics

Unipolar and bipolar energy, advanced bipolar technologies Ultrasonic energy

Laser

Close and open techniques

Trocar positioning

Coagulation and cutting

Dissection with water

Traction-counter-traction technique Dissection with forceps

Suturing

To end the procedure, closing 


\begin{tabular}{|c|c|c|c|c|}
\hline Characteristics & Values & $n(\%)$ & Mean & Range \\
\hline $\begin{array}{l}\text { Age, y } \\
\text { University district }\end{array}$ & $\begin{array}{l}\text { Helsinki } \\
\text { Tampere } \\
\text { Turku } \\
\text { Kuopio } \\
\text { Oulu } \\
\text { (Missing) }\end{array}$ & $\begin{aligned} 32 & (55) \\
10 & (17) \\
5 & (9) \\
6 & (10) \\
4 & (7) \\
1 & (2)\end{aligned}$ & 33.3 & $25-40$ \\
\hline Working history, mo & $\begin{array}{l}\text { Local hospital } \\
\text { University hospital } \\
\text { Surgery clinic }\end{array}$ & $\begin{array}{l}56(97) \\
27(47) \\
44(76)\end{array}$ & $\begin{array}{l}20.2 \\
13.4 \\
6\end{array}$ & $\begin{array}{l}2-46 \\
2-34 \\
3-9\end{array}$ \\
\hline Training time in OB/GYN* & $\begin{array}{l}<18 \mathrm{mo} \\
18-36 \mathrm{mo} \\
>36 \mathrm{mo}\end{array}$ & $\begin{array}{l}23(40) \\
19(33) \\
16(28)\end{array}$ & & \\
\hline Trained with & $\begin{array}{l}\text { Box trainer } \\
\text { Virtual simulator } \\
\text { Animal laboratory } \\
\text { Internet course } \\
\text { Two or more } \\
\text { None }\end{array}$ & $\begin{aligned} & 21(36) \\
& 28(48) \\
& 9(16) \\
& 2(3) \\
& 19(33) \\
& 21(36)\end{aligned}$ & & \\
\hline
\end{tabular}

*Obstetrics and gynecology.

Spearman's rho for nonparametric variables, and the Kruskal-Wallis test. We compared the precourse and postcourse questionnaire scores by using the Independentsamples $t$-test for parametric and the Mann-Whitney $U$ test for nonparametric variables.

\section{RESULTS}

Of the contacted residents $(n=154), 66$ announced their willingness to participate, and 58 (38\%) of them replied to the first questionnaire. Participants were from all 5 University districts, although 55\% were from the Helsinki area, being the largest unit for specialist training. The mean age was 33 years (Table 2), and the mean experience in $\mathrm{OB} /$ GYN was 26 months (range: 4-56 mo). Approximately $40 \%$ of the participants had worked in a gynecological department for less than 18 months, and $53 \%$ of the participants had done $<10$ of both adnexal operations and laparoscopic hysterectomies. Overall 17 (29\%) participants had done 10 to 30 adnexal operations, but $<10$ laparoscopic hysterectomies, whereas $10(17 \%)$ had performed $>30$ adnexal operations or 10 to 30 each, of adnexal operations and laparoscopic hysterectomies. The participants' surgical experience in general and in gynecological laparoscopic surgery according to training time in OB/GYN is shown in Table 3.

Furthermore, 33 (57\%) of the 58 participants replying the first questionnaire, replied to the second questionnaire (Table 4). These answers came from all University districts. More experienced residents (training time 18-36 mo) and the most experienced (training time $>36 \mathrm{mo}$ ) answered comparably more often (63\% and $56 \%$, respectively) than less experienced ones (52\%). Most (67\%) respondents had not worked in an operative unit during the study, 7 respondents had worked for 1 month, and 4 respondents for 2 months or more. Almost all (97\%) of the trainees rated the usefulness of the course high, 4 or 5 on the Likert scale of 1 to 5 , and all participants intended to return to the course.

The results from questionnaires 1 and 2, precourse and postcourse, are shown in the Figure, as grouped by months of training in $\mathrm{OB} / \mathrm{GYN}$. The scores increased significantly in every group. In the less experienced group $(<18 \mathrm{mo})$, the mean score increased from 81.9 to 89.3 ( $\mathrm{p}=0.009$ ), in the middle group (18-36 mo) from 90.4 to 97.9 ( $\mathrm{p}=$ $0.003)$, and in the most experienced group ( $>36 \mathrm{mo}$ ) from 94.8 to $100.0(\mathrm{p}=0.017)$.

Based on downloads during the first 3-year period, the section "Gynecological operations" was the most popular. The most downloaded single page was "Endometriosis" with more than 26,000 downloads, followed by "Ovarian operations" and "Laparoscopic prolapse surgery" with 24,000 and 12,000 downloads, respectively. All of these pages were in the top 75 most downloaded pages of all Duodecim web courses $(n=61)$. The second most popular section was "Pelvic anatomy" with 6500 downloads in "Normal anatomy" and 5400 in "Pathological anatomy." In the years 2013 and 2014, most pages in "Operative phases" were downloaded 500 to 1500 times a year, and pages concerning complications 600 to 1100 times a year. Pages on the very basics were also downloaded 500 to 1200 times a year.

\section{DISCUSSION}

We demonstrated at each experience level a statistically significant knowledge gain after completing the web course. 
TABLE 3. Participants' Surgical Experience According to Months of Training in Obstetrics and Gynecology

\begin{tabular}{|c|c|c|c|c|c|c|c|c|c|}
\hline \multirow[b]{2}{*}{ Training Time, mo } & \multicolumn{3}{|c|}{$\begin{array}{l}\text { Numbers of Operations } \\
\text { Done in General Surgery }\end{array}$} & \multicolumn{3}{|c|}{$\begin{array}{l}\text { Numbers of Laparoscopic } \\
\text { Adnexal Operations Done }\end{array}$} & \multicolumn{3}{|c|}{$\begin{array}{l}\text { Numbers of Laparoscopic } \\
\text { Hysterectomies Done }\end{array}$} \\
\hline & $<10$ & $10-30$ & $>30$ & $<10$ & $10-30$ & $>30$ & $<10$ & $10-30$ & $>30$ \\
\hline $\begin{array}{l}<18(n=23) \\
18-36(n=19) \\
>36(n=16)\end{array}$ & $\begin{array}{l}21 \\
19 \\
16\end{array}$ & $\begin{array}{l}2 \\
0 \\
0\end{array}$ & $\begin{array}{l}0 \\
0 \\
0\end{array}$ & $\begin{array}{r}20 \\
10 \\
2\end{array}$ & $\begin{array}{r}2 \\
9 \\
12\end{array}$ & $\begin{array}{l}1 \\
0 \\
2\end{array}$ & $\begin{array}{l}21 \\
16 \\
11\end{array}$ & $\begin{array}{l}2 \\
3 \\
5\end{array}$ & $\begin{array}{l}0 \\
0 \\
0\end{array}$ \\
\hline
\end{tabular}

The less experienced postcourse scores reached the level of middle group precourse, and the middle group exceeded the most experienced precourse level. The less experienced residents seem to benefit most, which is expected with a basic course such as this one. In the postcourse questionnaire, $79 \%$ of the participants rated the course usefulness as 5 on the Likert scale of 1 to 5 , and all participants intended to repeat the course at least partially. As there were 675 specialists in Obstetrics and Gynecology in Finland at the end of 2014 (The Finnish Medical Association), in addition to approximately 100 residents, the high numbers of web course downloads show an obvious need for a national easy access course. As the most popular websites covered advanced surgery (endometriosis and laparoscopic prolapse surgery), it is likely that specialists have also taken advantage of the course.

TABLE 4. Results in the Second Questionnaire

\begin{tabular}{|c|c|c|c|c|c|c|}
\hline Participants & Score & Age, y & $\begin{array}{c}\text { University } \\
\text { District }\end{array}$ & $\begin{array}{c}\text { Usefulness of the } \\
\text { Course, Likert } \\
\text { Scale 1-5 } \\
\end{array}$ & $\begin{array}{l}\text { Intend to } \\
\text { Repeat the } \\
\text { Course }\end{array}$ & $\begin{array}{c}\text { Working in Operative } \\
\text { Unit During the } \\
\text { Study, mo }\end{array}$ \\
\hline \multicolumn{7}{|c|}{ Training time $<18 \mathrm{mo}$} \\
\hline 1. & 85 & 29 & Oulu & 5 & Yes & 0 \\
\hline 2. & 99 & 38 & Helsinki & 5 & Yes & 1 \\
\hline 3. & 79 & 37 & Oulu & 5 & Yes & 3 \\
\hline 4. & 91 & 27 & Tampere & 5 & Yes & 1 \\
\hline 5. & 98 & 27 & Helsinki & 3 & Yes & 0 \\
\hline 6. & 95 & 33 & Helsinki & 5 & Yes & 0 \\
\hline 7. & 102 & 28 & Helsinki & 5 & Yes & 0 \\
\hline 8. & 85 & 30 & Tampere & 5 & Yes & 0 \\
\hline 9. & 89 & 31 & Helsinki & 5 & Yes & 0 \\
\hline 10. & 94 & 32 & Helsinki & 5 & Yes & 0 \\
\hline 11. & 77 & 38 & Helsinki & 4 & Yes & 0 \\
\hline \multirow{2}{*}{\multicolumn{7}{|c|}{ Training time $18-36 \mathrm{mo}$}} \\
\hline & & & & & & \\
\hline 13. & 86 & 35 & Tampere & 5 & Yes & 0 \\
\hline 14. & 98 & 28 & Turku & 5 & Yes & 1 \\
\hline 15. & 98 & 31 & Tampere & 5 & Yes & 1 \\
\hline 16. & 99 & 35 & Helsinki & 4 & Yes & 0 \\
\hline 17. & 93 & 34 & Kuopio & 5 & Yes & 0 \\
\hline 18. & 103 & 35 & Tampere & 5 & Yes & 4 \\
\hline 19. & 103 & 41 & Helsinki & 5 & Yes & 0 \\
\hline 20. & 106 & 34 & Helsinki & 5 & Yes & 0 \\
\hline 21. & 96 & 31 & Tampere & 5 & Yes & 0 \\
\hline 22. & 96 & 31 & Turku & 5 & Yes & 1 \\
\hline 23. & 97 & 29 & Helsinki & 5 & Yes & 2 \\
\hline 24. & 101 & 41 & Helsinki & 5 & Yes & 0 \\
\hline \multicolumn{7}{|c|}{ Training time $>36 \mathrm{mo}$} \\
\hline 25 . & 103 & 35 & Helsinki & 4 & Yes & 0 \\
\hline 26. & 104 & 37 & Tampere & 5 & Yes & 1 \\
\hline 27. & 97 & 37 & Kuopio & 5 & Yes & 0 \\
\hline 28. & 107 & 38 & Helsinki & 5 & Yes & 1 \\
\hline 29. & 96 & 38 & Tampere & 5 & Yes & 0 \\
\hline 30. & 105 & 33 & Helsinki & 5 & Yes & 0 \\
\hline 31. & 104 & 40 & Helsinki & 5 & Yes & 3 \\
\hline 32. & 97 & 36 & Helsinki & 4 & Yes & 0 \\
\hline 33. & 88 & 40 & Turku & 4 & Yes & 0 \\
\hline
\end{tabular}




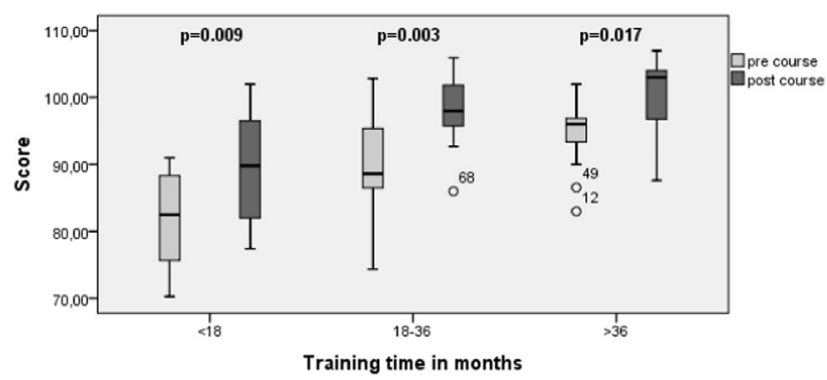

FIGURE. Scores in precourse and postcourse questionnaires with $p$ values according to training time in obstetrics and gynecology.

Our web course contains information on a broad range of topics, starting with very basic anatomy and with instrumentation and extending to surgical techniques and complications. This information has traditionally been learned over time in books and lectures, and during clinical work. In a study evaluating the best approach to educate about the common surgical condition of hemorrhoids (13), the e-learning group increased their knowledge significantly more than the lecture group. Thus, e-learning is also suitable in surgical education, and the advantages include reduced demands on teaching time. ${ }^{13}$ In this study, the elearning group found it easy to use the website, and its usefulness was graded as 6 on the Likert scale of 1 to 7 . This is in line with our study, where the participants were also very satisfied with the course, and the high numbers of website downloads indicate its usefulness. High levels of website usage have been reported in a program to prevent surgical infections, where an e-learning program was used in a blended educational approach. ${ }^{14}$ They listed the advantages of e-learning as the ease of access, 24-hour availability, and better-structured educational material. All of these features can be applied to our course as well. Thus, the web course is a convenient way to offer systematic, standardized didactics for all the trainees.

In a study evaluating a video-based curriculum for laparoscopic biliary surgery, ${ }^{15}$ a significant increase in skills was detected both in the basic and in the advanced modules. The participating rates were $37 \%$ and $62 \%$, respectively, and the best compliance was at the institution in which the module was a mandatory part of the curriculum. In our evaluation, the completion rate was at the same level. This is in concordance with previous studies, indicating that voluntary participation leads to poor completion rates. ${ }^{16}$

In a systematic review of e-learning in surgical education, ${ }^{8} 38$ studies were evaluated according to 3 different intervention themes: case-based, theoretical knowledge, and surgical skills. Theoretical knowledge as intervention was used in 18 studies, and participants included medical or dental students and surgical residents. Most of the studies showed a gain in knowledge, but not every study had a preintervention test, and only 7 studies had a control group. Although our study also lacked a control group, we used precourse and postcourse questionnaires with both qualitative and quantitative information. Our sample size was moderate, with a response rate of approximately $60 \%$. Obviously, there is a need for well-designed randomized controlled trials in the future.

Our study has several limitations. First, only $38 \%$ of the invited residents participated in the study. As registration for specialist training is unregulated, the number 154 also includes doctors who have already graduated or have changed specialty. Hence, the exact number of OB/GYN residents is impossible to count, and the correct participation rate is higher. Nevertheless, it is clear that only motivated residents take part in a study like this. Second, since the study was carried out anonymously, to gain as many participants as possible, the precourse and postcourse forms could not be connected as pairs. The dropout percentage was rather high, and we could not compare the dropout group with participants who finished the study. It is likely that the most motivated participants took the course. Third, the study was carried out via e-mail, and even though the participants were instructed to fill in the forms by themselves without help from others or literature, this could not be controlled. Fourth, 33\% of the participants had served in an operating unit in the spring of 2012, and this may have increased their postcourse skills. On the contrary, all of the participants have taken on-call duties and have been exposed to operating room work. And finally, we did not have a control group, as the aim was to evaluate the course effectiveness between residents at various levels of clinical experience.

\section{CONCLUSION}

We built a web-based comprehensive course suitable for integration into the Finnish gynecological laparoscopic curriculum. It is a feasible tool to be used as a cognitive part of a national certificate for trainees. Combined with a simulator training program, it could potentially serve as a basic curriculum in laparoscopic surgery. In the future, the effectiveness of such programs need to be evaluated.

\section{FUNDING}

The study was supported by University of Helsinki, the Finnish Society of Gynecological Surgery, and special governmental grant for health sciences research.

\section{REFERENCES}

1. Elbadrawy M, Majoko F, Gasson J. Impact of Calman system and recent reforms on surgical training in gynaecology. J Obstet Gynaecol. 2008;28(5):474-477. 
2. Peters JH, Fried GM, Swanstrom LL, et al. Development and validation of a comprehensive program of education and assessment of the basic fundamentals of laparoscopic surgery. Surgery. 2004;135:21-27.

3. Campo R, Molinas CR, DeWilde RL, et al. Are you good enough for your patients? The European certification model in laparoscopic surgery FVV ObGyn. 2012;4(2):95-101.

4. Burden C, Oestergaard J, Larsen CR. Intergrating of laparoscopic virtual-reality simulation into gynaecology training. BJOG. 2011;118(suppl 3):5-10.

5. Shaw C, Tan S. Integration of mobile technology in educational materials improves participation: creation of a novel smartphoneapplication for resident education. J Surg Educ. 2015;72(4):670-673.

6. Eckleberry-Hunt J, Tucciarone J. The challenges and opportunities of teaching generation Y. J Grad Med Educ. 2011;3(4):458-461.

7. Harandi SR. Effects of e-learning on students' motivation. Procedia Soc Behav Sci. 2015;181:423-430.

8. Jayakumar N, Brunckhorst O, Dasgupta P, Khan MS, Ahmed K. e-Learning in surgical education: a systematic review. J Surg Educ. 2015;72(6):1145-1157.

9. Ellaway R, Masters K. AMEE Guide 32: e-learning in medical education. Part 1: learning, teaching and assessment. Med Teach. 2008;30(5):455-473.

\section{SUPPLEMENTARY INFORMATION}

Supplementary data associated with this article can be found in the online version at http://dx.doi.org/10.1016/j.jsurg. 2016.12.007.
10. Thorne CJ, Lockey AS, Bullock I, Hampshire S, Begum-Ali S, Perkins GD. e-Learning in advanced life support-an evaluation by the Resuscitation Council (UK). Resuscitation. 2015;90:79-84.

11. Ritter EM, Scott DJ. Design of a proficiency-based skills training curriculum for the fundamentals of laparoscopic surgery. Surg Innov. 2007;14(2):107-112.

12. Duodecim.fi [Internet]. Gynekologisen laparoskopian perusteet. [Basics in gynecological laparoscopy] [in Finnish]. Available at: 〈http://www.terveysportti.fi/koti sivut $/$ sivut.koti?p_sivusto $=640\rangle$.

13. Bhatti I, Jones K, Richardson L, Foreman D, Lund J, Tierney G. E-learning vs lecture: which is the best approach to surgical teaching? Colorectal Dis. 2011;13 (4):459-462.

14. McHugh SM, Corrigan M, Dimitrov B, et al. A targeted e-learning program for surgical trainees to enhance patient safety in preventing surgical infections. J Contin Educ Health Prof. 2010;30(4):257-259.

15. Fearing N, Bachman $S$, Holzman M, Scott D, Brunt M. Evaluation of a video-based curriculum for laparoscopic biliary surgery: a pilot study from the SAGES MIS Web Learning Center. Surg Endosc. 2010;24 (12):3141-3143.

16. Kolkman W, Wolterbeek R, Jansen F. Gynecological laparoscopy in residency training program. Surg Endosc. 2005;19:1498-1502. 